\title{
When Physicians Say No: Predictors of Request Denial and Subsequent Patient Satisfaction
}

\author{
Elizabeth M. Magnan, MD, PhD, Peter Franks, MD, Anthony Jerant, MD, \\ Richard L. Kravitz, MD, MSPH, and Joshua J. Fenton, MD, MPH
}

Background: Physician denial of patient requests is associated with lower patient satisfaction. Our objective was to explore factors that influence physician request denial and patient satisfaction after request denial.

Methods: Cross-sectional observational study of 1141 adult patients seen during 1319 outpatient visits with 56 primary care physicians. We measured patients' postvisit self-report of requests and request fulfillment, visit satisfaction, sociodemographics, health status, symptom burden, life satisfaction, medical skepticism, and whether patients saw their usual physician and a faculty or resident physician. We used mixed-effects regression analyses to identify predictors of request denial and visit satisfaction among patients who had a request denied.

Results: Patients made at least 1 request at 867 visits (65.7\%) with at least 1 denied request reported at 182 visits $(\mathbf{2 1 . 0 \% )}$. Patients who saw their usual physician were less likely to report a request denial (adjusted Odds Ratio [aOR], 0.61; 95\% CI, 0.42 to 0.88 ), and patients with the highest symptom burden (aOR, 2.21; 95\% CI, 1.38 to 3.55) or greater medical skepticism (aOR, 1.35; 95\% CI, 1.03 to 1.78) were more likely to report request denials. After request denials, patients seeing their usual physicians reported significantly greater visit satisfaction compared with not seeing their usual physician (adjusted percentile rank in visit satisfaction: $12.4 \%$; 95\% CI, 3.5\% to 21.2\%).

Conclusions: Approximately one fifth of visits in primary care have a denied request. Having an office visit with one's usual physician is associated with reduced likelihood of request denial and may mitigate the adverse impacts of request denial on patient visit satisfaction. (J Am Board Fam Med 2020;33: 51-58.)

Keywords: Cross-Sectional Studies, Outpatients, Patient Satisfaction, Personal Satisfaction, Physician-Patient Relations, Primary Care Physicians, Regression Analysis, Self Report

Patients make requests of their physician at many primary care office visits, including requests for medications, laboratory tests, imaging tests, or

This article was externally peer reviewed.

Submitted 6 June 2019; revised 2 August 2019; accepted 10 August 2019.

From the Department of Family and Community Medicine (EMM, PF, AJ, JJF), the Center for Healthcare Policy and Research (EMM, PF, AJ, RLK, JJF), and the Division of General Medicine, Department of Internal Medicine (RLK), University of California, Davis Medical Center, Sacramento, CA.

Funding: This work was supported by the University of California Davis Department of Family and Community Medicine.

Conflict of interest: none declared.

Corresponding author: Elizabeth Magnan, MD, PhD, Department of Family and Community Medicine, University of California, Davis Health System, 4860 Y Street, Suite 2300, Sacramento, CA 95817 (E-Mail: emagnan@ucdavis. edu). specialty referrals. ${ }^{1,2}$ Prior studies have shown that physician denial of requests is associated with lower patient satisfaction. ${ }^{1-5}$ However, we know little about patient characteristics that may be associated with denial of their requests, or which factors predict lower patient satisfaction in the context of a denied request. In the era of medical stewardship, physicians must deny some patient requests for low-value or inappropriate services. ${ }^{6}$ Meanwhile, patient satisfaction scores are employed as a measure of care quality and are increasingly considered in clinician compensation plans. ${ }^{7}$ During clinical encounters, a tension may arise between evidence-based medicine, highvalue care, physician self interest, and patient-centeredness. We need to understand the factors associated with higher patient satisfaction after request 
denial as these may point the way to interventions to resolve this tension.

Previous work has shown that patients with low trust in their physician or who are unmarried are more likely to report denied requests. ${ }^{1}$ In the current study, we added to this literature by measuring associations between additional patient characteristics and physician denial of requests, including patient sociodemographic characteristics, health status, patient health attitudes, and continuity of care (seeing the patient's usual physician). We also examined patient characteristics associated with patient satisfaction when a request has been denied. While previous studies on patient satisfaction have shown that patient-level characteristics such as age, ${ }^{8-11}$ life satisfaction, ${ }^{9,12}$ medical skepticism, ${ }^{9}$ health status, ${ }^{8,10}$ and care continuity ${ }^{8,9,13-15}$ are associated with patient satisfaction overall, we do not know if specific patient characteristics are associated with satisfaction in the context of denied requests. As patient satisfaction is driven, at least in part, by physician communication during a visit, ${ }^{16}$ our results may have implications for optimizing physician communication when denying requests.

In this study, we used data collected from adult patients at primary care office visits to examine whether patient characteristics are associated with physician denial of patient requests, and, in the subsample of patients who had a request denied, with patient satisfaction measures. Our goal was to understand predictors of both request denial and patient satisfaction after request denial.

\section{Methods}

\section{Design, Setting, and Subjects}

We surveyed patients and reviewed the electronic health record after ambulatory family medicine encounters in a single academic family medicine clinic from July 2015 to April 2016. Three days a week during the study period, trained research assistants recruited a convenience sample of patients in the clinic waiting room before outpatient visits scheduled with 45 resident or 11 faculty family physicians. Patient eligibility criteria were age 18 years or older, ability to read English to complete an article or tablet-based survey, and scheduled to see a family physician at the clinic that day. An individual patient could participate up to 6 times. $\mathrm{Pa}$ tients received a $\$ 10$ gift card each time they participated.
We used LimeSurvey software on a tablet computer to administer the survey immediately after the clinic visits, and this software provided data completeness and quality checks in real-time to improve data collection. Patients completed informed consent before study participation, and the University of California, Davis (UCD) Institutional Review Board approved the study. The study funders had no role in the study design or interpretation of the results.

\section{Outcome Variables}

\section{Patient Requests}

Participants completed a survey asking whether they made 1 or more requests for several distinct categories of services, and if they felt their physician had completely fulfilled, incompletely fulfilled, denied, or ignored the request (patient self-report of request denial) using questions and request categories derived from previous studies. ${ }^{3,17,18}$ These request categories included new pain medication prescriptions, antibiotic prescriptions, other new medication prescriptions, laboratory testing, radiology testing, other testing (e.g., sleep study), and referrals to specialists. Within each request category, we categorized incompletely fulfilled, denied, or ignored as "denied."

\section{Patient Satisfaction}

We measured patient satisfaction with 6 items derived from the individual visit version of the Consumer Assessment of Health care Providers and Systems Clinician \& Group Survey. ${ }^{19}$ The first 4 items asked whether the physician 1) gave easy-tounderstand information, 2) knew important information about the patients' medical history, 3) showed respect for what the patient had to say, and 4) spent enough time with the patient. The fifth item asked whether the patient would recommend the primary care physician to family and friends, and the sixth item requested that the patient rate the doctor from worse $(0 / 10)$ to best $(10 / 10)$ possible doctor. We created a standardized scale in which higher numbers indicated higher patient satisfaction by averaging the z-score for each item because items were highly correlated (Cronbach's $\alpha=0.81$ ) and loaded onto a single latent construct in factor analyses. ${ }^{9}$ 


\section{Patient Characteristics}

\section{Patient Sociodemographics and Visit Physician}

Through the survey, we collected sociodemographic measures including patient age, sex, race/ethnicity, and education, and queried whether the patient saw the physician they usually see (patient self-report of usual physician). ${ }^{20} \mathrm{We}$ also collected marital status because it may influence patient satisfaction through impacts on mental health or social support. ${ }^{21} \mathrm{We}$ determined the visit physician through the electronic health record and classified each as a resident or faculty physician. The sociodemographic and visit variables were all categorical except for age (which was coded as a continuous variable). Payor mix was not available, and includes commercial insurance, Medicare and Medicaid, without self pay.

\section{Patient Mental and Physical Health Status}

We measured self-reported health status (poor or fair vs good, very good, or excellent $)^{20}$ and mental health using the 5-item Mental Health Inventory-5, an accurate measure of both depression and anxiety (range, 0 to 100 from worst to best mental health). ${ }^{22}$

\section{Patient Symptom Burden, Global Life Satisfaction, and Medical Skepticism}

We included 3 items regarding the extent to which patients are burdened, bothered, or worried about their symptoms, as symptom burden has predicted difficult patient-physician encounters. ${ }^{23}$ Because the items were highly correlated, we created a 3 -item scale in which a higher score signifies greater symptom burden (range, 3 to 15; Cronbach's $\alpha=0.83$ ). We recoded symptom burden as a categorical variable (low, middle, and high). Through the survey, we also assessed 2 patientlevel dispositional factors that could affect patient satisfaction: global life satisfaction and medical skepticism. We assessed global life satisfaction using the 5-item Satisfaction with Life Scale (range, 5 to 35 ), a validated measure of subjective wellbeing with high temporal reliability. ${ }^{24} \mathrm{We}$ assessed medical skepticism regarding medical care through a 4-item measure that predicts health care utilization and healthful lifestyle choices (range, 1 to 5). ${ }^{25}$ The items were 1) I can overcome most illness without a medically trained professional; 2) Home remedies are often better than drugs prescribed by a doctor; 3) If I get sick, it is my own behavior that determines how soon I will get well again; 4) I under- stand my health better than most doctors do. We included global life satisfaction and medical skepticism as continuous variables.

We collected patient sociodemographic characteristics, medical skepticism, and global life satisfaction at the first visit for patients with repeated visits and carried the values forward to reduce survey burden. We collected visit physician, symptom burden, self-reported physical health and self-reported mental health at each visit.

\section{Analyses}

We conducted statistical analyses using Stata Version 14.2 (College Station, TX). We used summary statistics to describe the total study population and compare the subsample who reported 1 or more requests denied to the subsample who did not report any request denied, using $t$-tests or $\chi^{2}$ tests as appropriate. We then used logistic regression to model the binary outcome of request denial (any vs none) as function of the following independent variables: patient sociodemographic characteristics, visit physician (usual doctor and resident vs faculty), physical health, mental health, symptom burden, medical skepticism, and life satisfaction. For the analyses of the outcome of patient satisfaction among patients who had 1 or more requests denied, we used linear regression with the same independent variables. Because patient satisfaction scores were highly skewed, we transformed the scores into percentile ranks (ranging from the worst rank of 0 to the best rank of 100). ${ }^{26}$ Because visits were cross-nested within patients and physicians, we used mixed-effects models that corrected standard errors for the nested structure of the data. Because the number of visits with a request denied was small, we aggregated denied requests rather than categorizing denied requests by type. As a sensitivity analysis, we used mixed-effects negative binomial regression to model a count of requests denied as a function of the independent variables. For hypothesis tests, we selected an $\alpha$ value of 0.05 to determine statistical significance.

\section{Results}

A total of 1141 adult patients making 1319 outpatient visits (mean, 1.2 visits/patient) with 56 family physicians (45 resident and 11 faculty) were included. Of 1319 visits, $867(65.7 \%)$ visits included at least 1 request, and 1 or more requests were denied in 182 visits (21.0\% of visits with requests). Of these 182 
visits, patients reported 1 denial in 144 visits (79\%), 2 denials in 30 visits (17\%), and 3 denials at 8 visits (4\%). There were 228 denials total, across the 8 categories: lab test (42), radiology test (48), other test (14), new medication (nonantibiotic, nonpain medication) (40), pain medication (48), antibiotic (10), and referral (26.) The sample was mostly female and in good self-reported health, and exhibited a range of education levels. Half of the study patients saw their usual physician (Table 1).

\section{Predictors of Request Denial}

Table 2 shows predictors of patients' reporting denial of at least 1 request during a visit. Patients

Table 1. Patient Characteristics by Whether a Request was Denied for Visits with a Patient Request $(n=867$ Visits)

\begin{tabular}{|c|c|c|c|c|}
\hline & $\begin{array}{l}\text { All Visits with } \\
\text { One or More } \\
\text { Requests }\end{array}$ & $\begin{array}{c}\text { Patients Who Did } \\
\text { Not Report a } \\
\text { Denial }\end{array}$ & $\begin{array}{l}\text { Patients Who Reported } \\
\text { One or More Denials }\end{array}$ & $P$-Value \\
\hline $\mathrm{n}$ & 867 & 685 & 182 & \\
\hline Age, mean (SD) & $46.4(15.8)$ & $46.7(16.0)$ & $45.2(14.8)$ & .25 \\
\hline Male gender & $267(30.8 \%)$ & $215(31.4 \%)$ & $52(28.6 \%)$ & .46 \\
\hline \multicolumn{5}{|l|}{ Race/ethnicity } \\
\hline White & $399(46.0 \%)$ & $312(45.5 \%)$ & $87(47.8 \%)$ & .74 \\
\hline Hispanic & $208(24.0 \%)$ & $164(23.9 \%)$ & $44(24.2 \%)$ & \\
\hline Black & $104(12.0 \%)$ & $86(12.6 \%)$ & $18(9.9 \%)$ & \\
\hline Asian & $53(6.1 \%)$ & $39(5.7 \%)$ & $14(7.7 \%)$ & \\
\hline Other/multiple races & $75(8.7 \%)$ & $60(8.9 \%)$ & $15(8.2 \%)$ & \\
\hline Decline to state & $28(3.2 \%)$ & $24(3.5 \%)$ & $4(2.2 \%)$ & \\
\hline \multicolumn{5}{|l|}{ Education level } \\
\hline HS/GED or less & $170(19.6 \%)$ & $134(19.6 \%)$ & $36(19.7 \%)$ & .33 \\
\hline Some college & $315(36.3 \%)$ & $249(36.4 \%)$ & $66(36.3 \%)$ & \\
\hline College grad & $184(21.2 \%)$ & $137(20.0 \%)$ & $47(25.8 \%)$ & \\
\hline$>$ College & $198(22.8 \%)$ & $165(24.1 \%)$ & $33(18.1 \%)$ & \\
\hline \multicolumn{5}{|l|}{ Marital status } \\
\hline $\begin{array}{l}\text { Married or domestic } \\
\text { partnership }\end{array}$ & $361(41.6 \%)$ & $287(41.9 \%)$ & $74(40.7 \%)$ & .40 \\
\hline Divorced & $125(14.4 \%)$ & $98(14.3 \%)$ & $27(14.8 \%)$ & \\
\hline Unmarried couple & $86(9.9 \%)$ & $75(10.9 \%)$ & $11(6.0 \%)$ & \\
\hline Never married & $207(23.9 \%)$ & $158(23.1 \%)$ & $49(26.9 \%)$ & \\
\hline Separated & $30(3.5 \%)$ & $22(3.2 \%)$ & $8(4.4 \%)$ & \\
\hline Widowed & $58(6.7 \%)$ & $45(6.6 \%)$ & $13(7.7 \%)$ & \\
\hline Saw usual physician (self-reported) & $442(51.0 \%)$ & $365(53.3 \%)$ & $77(42.3 \%)$ & .008 \\
\hline Patient saw faculty physician & $211(24.3 \%)$ & $176(25.7 \%)$ & $35(19.2 \%)$ & .07 \\
\hline $\begin{array}{l}\text { Self-reported physical health good } \\
\text { or better }\end{array}$ & $663(76.5 \%)$ & $534(78.0 \%)$ & $129(70.9 \%)$ & .04 \\
\hline Mental Health index, mean (SD) & $72.5(19.0)$ & $73.2(18.9)$ & $69.9(56.0,84.0)$ & .04 \\
\hline \multicolumn{5}{|l|}{ Symptom burden } \\
\hline Low & $240(27.7 \%)$ & $203(29.6 \%)$ & $37(20.3 \%)$ & $<.001$ \\
\hline Mid & $222(25.6 \%)$ & $192(28.0 \%)$ & $30(16.5 \%)$ & \\
\hline High & $405(46.7 \%)$ & $290(42.3 \%)$ & $115(63.2 \%)$ & \\
\hline Medical skepticism, mean (SD) & $3.0(0.66)$ & $3.0(0.65)$ & $3.1(0.70)$ & .06 \\
\hline Life satisfaction, mean (SD) & $25.1(6.50)$ & $25.1(6.5)$ & $25.1(6.3)$ & .99 \\
\hline
\end{tabular}

SD, standard deviations; HS/GED, High School/General Educational Development.

Saw usual doctor: patient answered on survey that they saw the usual doctor they see for medical care (patient self-report of usual doctor).

Mental Health index: higher is better self-reported mental health (range, 4 to 100).

Symptom burden: higher is great symptom burden.

Medical skepticism: higher value is more skeptical (range, 1 to 5 ).

Life satisfaction: higher value is more satisfied (range, 5 to 35 ). 
Table 2. Predictors of Physician Denial of One or More Patient Requests Among All Visits with a Request $(\mathrm{n}=867)$

\begin{tabular}{|c|c|c|}
\hline & \multicolumn{2}{|c|}{$\begin{array}{l}\text { Patients Who Reported } \geq 1 \\
\text { Requests Denied }\end{array}$} \\
\hline & aOR (95\% CI) & $P$-Value \\
\hline Age & $1.00(0.99,1.01)$ & .92 \\
\hline $\begin{array}{l}\text { Male gender (female }= \\
\text { reference) }\end{array}$ & $1.00(0.68,1.49)$ & .99 \\
\hline \multicolumn{3}{|l|}{ Race/ethnicity } \\
\hline White & reference & \\
\hline Hispanic & $0.74(0.47,1.18)$ & .21 \\
\hline Black & $0.64(0.35,1.17)$ & .15 \\
\hline Asian & $1.37(0.67,2.81)$ & .38 \\
\hline Other/multiple races & $0.74(0.38,1.49)$ & .38 \\
\hline Decline to state & $0.59(0.19,1.83)$ & .36 \\
\hline \multicolumn{3}{|l|}{ Education level } \\
\hline HS/GED or less & reference & \\
\hline Some college & $1.12(0.68,1.82)$ & .66 \\
\hline College grad & $1.38(0.80,2.37)$ & .25 \\
\hline$>$ College & $0.74(0.41,1.32)$ & .30 \\
\hline \multicolumn{3}{|l|}{ Marital status } \\
\hline Married or partnership & reference & \\
\hline Divorced & $0.93(0.54,1.60)$ & .80 \\
\hline $\begin{array}{l}\text { Member of unmarried } \\
\text { couple }\end{array}$ & $0.44(0.19,1.02)$ & .06 \\
\hline Never married & $0.99(0.53,1.87)$ & .99 \\
\hline Separated & $1.33(0.50,3.54)$ & .56 \\
\hline Widowed & $1.23(0.55,2.77)$ & .61 \\
\hline $\begin{array}{l}\text { Saw usual physician (self- } \\
\text { reported) }\end{array}$ & $0.61(0.42,0.88)$ & .009 \\
\hline Patient saw faculty physician & $0.72(0.44,1.16)$ & .18 \\
\hline $\begin{array}{l}\text { Self-reported physical health } \\
\text { good or better }\end{array}$ & $0.75(0.48,1.17)$ & .21 \\
\hline Mental Health index & $0.99(0.98,1.00)$ & .18 \\
\hline \multicolumn{3}{|l|}{ Symptom burden } \\
\hline Low & reference & \\
\hline Mid & $0.84(0.49,1.44)$ & .53 \\
\hline High & $2.21(1.38,3.55)$ & .001 \\
\hline Medical skepticism & $1.35(1.03,1.78)$ & .03 \\
\hline Life satisfaction & $1.03(0.99,1.07)$ & .06 \\
\hline
\end{tabular}

aOR, adjusted odds ratio; CI, confidence interval; HS/GED, High School/General Educational Development.

Saw usual doctor: patient answered on survey that they saw the usual doctor they see for medical care (patient self-report of usual doctor).

Mental Health index: higher is better self-reported mental health (range, 4 to 100).

Symptom Burden: higher is great symptom burden.

Medical Skepticism: higher value is more skeptical (range, 1 to 5 ).

Life Satisfaction: higher value is more satisfied (range, 5 to 35). were significantly more likely to report request denials if they were not seeing their usual physician, expressed greater symptom burden (high compared with low), or had greater medical skepticism. We found consistent results in a sensitivity analysis in which the count of denials was modeled using negative binomial regression (results not shown).

\section{Satisfaction After Request Denial}

Table 3 shows adjusted changes in the percentile rank in visit satisfaction associated with the independent variables among patients who reported request denials. After having 1 or more requests denied, patients who were seeing their usual physician, as compared with those not seeing their usual physician, had significantly higher visit satisfaction, as did patients who saw a faculty physician rather than a resident, and who had higher life satisfaction relative to patients with lower life satisfaction. In contrast, adjusted visit satisfaction after request denial was significantly lower among patients with more than a college education as compared with patients with a high school degree or less, and among patients with greater medical skepticism.

\section{Discussion}

We found that patients who made requests during primary care visits were more likely to report a request denial when seeing a physician other than their usual physician. Among patients reporting a request denial, patients were less likely to be satisfied with their visit if they were denied the request from a physician other than their usual physician.

There may be several potential explanations for the association between request denials and whether the patient and physician have an established relationship. Within established patient-physician relationships, greater trust may facilitate explicit and implicit communication, such that patients can more effectively and efficiently communicate their concerns and preferences, while physicians may more easily perceive and meet patients' needs and expectations. An association between lower patient trust in their physician and higher patient self report of request denial has been shown previously. ${ }^{1,27}$ In addition, a physician evaluating another physician's established patient might tend to offer simpler approaches to diagnosis and treatment, while deferring complex decisions about 
Table 3. Predictors of Patient Satisfaction Among Patients who Had at Least one Request Denied During the Visit $(n=182)$

\begin{tabular}{|c|c|c|}
\hline & $\begin{array}{l}\text { Adjusted Change } \\
\text { in Percentile } \\
\text { Rank in Visit } \\
\text { Satisfaction } \\
(95 \% \text { CI })\end{array}$ & $P$-Value \\
\hline Age (per year) & $0.2(-0.1,0.6)$ & .14 \\
\hline $\begin{array}{l}\text { Male gender (female }= \\
\text { reference) }\end{array}$ & $2.1(-6.8,10.9)$ & .65 \\
\hline \multicolumn{3}{|l|}{ Race/ethnicity } \\
\hline White & reference & \\
\hline Hispanic & $0.1(-9.8,10.0)$ & .98 \\
\hline Black & $-0.6(-14.4,13.1)$ & .93 \\
\hline Asian & $5.2(-9.8,20.3)$ & .50 \\
\hline Other/multiple races & $3.1(-11.3,17.5)$ & .67 \\
\hline Decline to state & $-19.1(-46.4,-8.1)$ & .17 \\
\hline \multicolumn{3}{|l|}{ Education level } \\
\hline HS/GED or less & reference & \\
\hline Some college & $-1.5(-12.4,9.3)$ & .78 \\
\hline College grad & $-9.7(-21.8,2.5)$ & .12 \\
\hline$>$ College & $-15.4(-29.2,-1.7)$ & .028 \\
\hline \multicolumn{3}{|l|}{ Marital status } \\
\hline $\begin{array}{l}\text { Married or partnership } \\
\text { (reference) }\end{array}$ & reference & \\
\hline Divorced & $8.6(-20.3,3.2)$ & .16 \\
\hline $\begin{array}{l}\text { Member of unmarried } \\
\text { couple }\end{array}$ & $-16.8(-36.1,2.5)$ & .09 \\
\hline Never married & $0.6(-12.7,13.8)$ & .93 \\
\hline Separated & $-15.6(-37.0,5.9)$ & .16 \\
\hline Widowed & $-8.0(-26.4,10.4)$ & .40 \\
\hline $\begin{array}{l}\text { Saw usual physician (self- } \\
\text { reported) }\end{array}$ & $12.4(3.5,21.2)$ & .006 \\
\hline Patient saw faculty physician & $11.7(0.7,22.7)$ & .036 \\
\hline $\begin{array}{l}\text { Self-reported physical health } \\
\text { good or better }\end{array}$ & $3.8(-6.5,14.1)$ & .45 \\
\hline $\begin{array}{l}\text { Mental Health index (per } \\
\text { point increase) }\end{array}$ & $0.1(-0.1,0.3)$ & .43 \\
\hline \multicolumn{3}{|l|}{ Symptom burden } \\
\hline Low (reference) & reference & \\
\hline Mid & $-1.8(-14.4,10.9)$ & .78 \\
\hline High & $1.4(-9.5,12.4)$ & .80 \\
\hline $\begin{array}{l}\text { Medical skepticism (per } \\
\text { point increase) }\end{array}$ & $-6.9(-12.7,-1.1)$ & .02 \\
\hline $\begin{array}{l}\text { Life satisfaction (per point } \\
\text { increase) }\end{array}$ & $1.0(0.2,1.8)$ & .03 \\
\hline
\end{tabular}

CI, confidence interval; HS/GED, High School/General Educational Development.

Saw usual doctor: patient answered on survey that they saw the usual doctor they see for medical care (patient self-report of usual doctor). Mental Health index: higher is better self-reported mental health (range, 4 to 100).

Symptom Burden: higher is great symptom burden.

Medical Skepticism: higher value is more skeptical (range, 1 to 5).

Life Satisfaction: higher value is more satisfied (range, 5 to 35 ). tests, treatments, or referrals to the patient's usual physician. Past work showed that physicians without previous knowledge of a patient are less likely to order medications or referrals. ${ }^{28}$

The finding that patients not visiting their usual physician were less satisfied in the context of a request denial than those visiting their usual physician reinforces the importance of continuity of care as fundamental to high-quality primary care. Previous findings have shown that continuity of care is associated with patient satisfaction in general. ${ }^{8,13-15}$ Previous work also has shown that denials of patient requests are associated with lower patient satisfaction. ${ }^{1,2}$ Our findings suggest that physician continuity may mitigate the adverse impact of request denials on patient satisfaction. Within continuity relationships, patients may feel confident that they may ask their usual physician to fulfill the denied request in the future if their symptoms or concerns persist, and may be more likely to accept a denial from a physician they know without reducing satisfaction in the visit.

Higher medical skepticism-an inclination to believe that medical care is unlikely to alleviate health concerns or is unnecessary-was also associated with a significantly increased likelihood of request denial and reduced patient satisfaction after denial. Patients with higher medical skepticism might make requests differently than other patients, in a way that is more challenging for a physician to understand as a request or fulfill. Past work has shown that the manner in which a patient initiates the request is related to its likelihood of being fulfilled. ${ }^{29}$ These patients might also be less likely to negotiate after an initial denial with a physician, or more likely to perceive a denial when that is not what the physician meant, leading these patients to report more denials. Patients with higher medical skepticism have been shown to have lower health care utilization that those with lower medical skepticism, and so a request for health care might be more important to patients who use health care less and believe in it less. ${ }^{25}$ Once these patients perceive a denial, they might be more likely to become dissatisfied with medical care, as the denial may reinforce their lower baseline opinions of medical care.

Patients with greater symptom burden were also more likely to report request denials. In our past work, ${ }^{30}$ more symptomatic patients were more likely to request multiple tests or treatments, plausibly in an effort to reduce symptom burden or mitigate uncertainty, and therefore may have a 
greater chance of having at least 1 request denied. The denial might be intentional (based on the physician's judgment that the service is unnecessary or premature) or unintentional (based on the physician's failure to recognize the request, which may not have been explicit and unambiguous).

After a request denial, patients were more likely to be satisfied with their care if they had higher life satisfaction compared with lower life satisfaction. Life satisfaction may be associated with attitudes toward medical care in general, and is not a factor that can be changed by physicians. We showed in previous work that higher life satisfaction was related to more patient requests during physician visits and to greater overall visit satisfaction, ${ }^{9,30}$ and other past work has shown the importance of life satisfaction as a stronger predictor of visit satisfaction than patient sociodemographic characteristics. ${ }^{12}$

Patients with the highest level of education, more than a college degree, were significantly more likely to be dissatisfied after a denial compared with patients with a high school education or less. Highly educated patients may be more likely to have done research before their visit to justify their request. ${ }^{31}$ Patients with more than a college degree may also be more accustomed to making autonomous career and life decisions so might respond negatively to request denials in medical settings.

We also found that seeing a faculty physician, rather than a resident, was associated with higher patient satisfaction after request denial. This is likely due to greater continuity of care with faculty physician-patient relationships compared with resident physician-patient relationships in the study clinic, due to the unpredictable schedules of residents and the shorter duration that they affiliated with the academic clinic compared with a faculty physicians. This may also reflect lower patient confidence in residents' recommendations, as many patients likely know that residents are in training and supervised by faculty.

Training in when and how to deny patient requests could lead to higher patient satisfaction after request denial. Past work showed that higher patient satisfaction after a denial when a patientcentered approach to deny the request was used compared with biomedical or direct refusal approaches. ${ }^{32}$ A study training residents in patientcentered approaches to request denial for medically inappropriate tests showed better patient satisfaction scores for new patients seeing residents who received training, but no difference in the use of patient-centered approaches or in request denials, compared with those who did not receive this training. ${ }^{33}$ Our findings showed that continuity of care is related to higher patient satisfaction after denial, suggesting that continuity as well as communication approaches matter for patient satisfaction after request denial. More work is needed to understand how communication around a denial occurs, with and without patient-doctor continuity, and how the discussion influences patient satisfaction scores, to develop effective resident training interventions.

There are limitations inherent to our study design. We measured patient requests and satisfaction during a single visit, and so were unable to examine outcomes longitudinally or to establish causation. In addition, while our sample was diverse, it was a convenience sample in a single academic practice; ideally the study should be repeated in other settings with different patient and physician populations. While the sample size was large enough to measure overall request denial, there were not enough denials to analyze request denial or satisfaction after request denial by request type (e.g., laboratory testing, radiograph, medication) or by faculty versus resident physician. Finally, the study was not designed to determine the medical appropriateness of the request denials nor the content of the discussion around the denial; this could be addressed in a future study.

Our study showed that primary care patients seeing their usual physicians were less likely to have a request denied and, if a request was denied, were more satisfied with their visit than patients not seeing their usual physicians. Augmenting continuity of care may improve patient satisfaction by developing the patient-physician relationship and supporting trustful conversations about the appropriateness of tests, treatments and referrals that patients request.

We are grateful to the following individuals, all whom were employed and compensated as study support staff at the University of California-Davis: Rimaben Cabrera, MSW, who managed the project and contributed to study recruitment and data collection; and Eliot Lee and Leyleh Salem for assistance in data collection.

To see this article online, please go to: http://jabfm.org/content/ 33/1/51.full.

\section{References}

1. Kravitz RL, Bell RA, Azari R, Krupat E, Kelly-Reif $\mathrm{S}$, Thom D. Request fulfillment in office practice: antecedents and relationship to outcomes. Med Care 2002;40:38-51. 
2. Jerant A, Fenton JJ, Kravitz RL, et al. Association of clinician denial of patient requests with patient satisfaction. JAMA Intern Med 2018;178:85-91.

3. Kravitz RL, Bell RA, Franz CE. A taxonomy of requests by patients (TORP): a new system for understanding clinical negotiation in office practice. Journal Fam Pract 1999;48:872-8.

4. Macfarlane J, Holmes W, Macfarlane R, Britten N. Influence of patients' expectations on antibiotic management of acute lower respiratory tract illness in general practice: questionnaire study. BMJ 1997;315:1211-4.

5. Rao JK, Weinberger M, Kroenke K. Visit-specific expectations and patient-centered outcomes: a literature review. Arch Fam Med 2000;9:1148-55.

6. Zikmund-Fisher BJ, Kullgren JT, Fagerlin A, Klamerus ML, Bernstein SJ, Kerr EA. Perceived barriers to implementing Individual Choosing Wisely ${ }^{\circledR}$ recommendations in two national surveys of primary care providers. J Gen Intern Med 2017;32:210-7.

7. Kupfer JM, Bond EU. Patient satisfaction and patient-centered care: necessary but not equal. JAMA 2012;308:139-40.

8. Batbaatar E, Dorjdagva J, Luvsannyam A, Savino MM, Amenta P. Determinants of patient satisfaction: a systematic review. Perspectives Pub Health 2017;137:89-101.

9. Fenton JJ, Jerant A, Kravitz RL, et al. Reliability of physician-level measures of patient experience in primary care. J Gen Intern Med 2017;32:1323-9.

10. Hekkert KD, Cihangir S, Kleefstra SM, van den Berg B, Kool RB. Patient satisfaction revisited: A multilevel approach. Soc Sci Med 2009;69:68-75.

11. Hall JA, Dornan MC. Patient sociodemographic characteristics as predictors of satisfaction with medical care: a meta-analysis. Soc Sci Med 1990;30:811-8.

12. Weiss GL. Patient satisfaction with primary medical care. Evaluation of sociodemographic and predispositional factors. Med Care 1988;26:383-92.

13. Hjortdahl P, Laerum E. Continuity of care in general practice: effect on patient satisfaction. BMJ 1992;304:1287-90.

14. Nutting PA, Goodwin MA, Flocke SA, Zyzanski SJ, Stange KC. Continuity of primary care: to whom does it matter and when? Ann Fam Med 2003;1:149-55.

15. Fan VS, Burman M, McDonell MB, Fihn SD. Continuity of care and other determinants of patient satisfaction with primary care. J Gen Intern Med 2005;20:226-33.

16. Flocke SA, Miller WL, Crabtree BF. Relationships between physician practice style, patient satisfaction, and attributes of primary care. J Fam Pract 2002;51: 835-40.

17. Kravitz RL. Measuring patients' expectations and requests. Ann Intern Med 2001;134(9 Pt 2):881-888.

18. Bell RA, Kravitz RL, Thom D, Krupat E, Azari R. Unmet expectations for care and the patient-physician relationship. J Gen Intern Med 2002;17:817-24.
19. Agency for Healthcare Quality and Research. CAPHS: Surveys and Tools to Advance Patient Care. 2016. Available from: http://www.ahrq.gov/ cahps/surveys-guidance/cg/index.html. Accessed November 11, 2016.

20. Instructions for Analyzing Data from CAHPS Surveys: Using the CAHPS Analysis Program Version 4.1. [Computer Program]. Version 4.12012.

21. Hewitt B, Turrell G, Giskes K. Marital loss, mental health and the role of perceived social support: findings from six waves of an Australian population based panel study. J Epidemiol Community Health 2012; 66:308-14.

22. Berwick DM, Murphy JM, Goldman PA, Ware JE Jr, Barsky AJ, Weinstein MC. Performance of a five-item mental health screening test. Med Care 1991;29:169-76.

23. Hinchey SA, Jackson JL. A cohort study assessing difficult patient encounters in a walk-in primary care clinic, predictors and outcomes. J Gen Intern Med 2011;26:588-94.

24. Diener E, Emmons RA, Larsen RJ, Griffin S. The Satisfaction With Life Scale. J Pers Assess 1985;49:71-5.

25. Fiscella K, Franks P, Clancy CM. Skepticism toward medical care and health care utilization. Med Care 1998;36:180-9.

26. Conover WJ, Iman RL. Rank transformations as a bridge between parametric and nonparametric statistics. Am Stat 1981;35:124-9.

27. Thom DH, Kravitz RL, Bell RA, Krupat E, Azari R. Patient trust in the physician: relationship to patient requests. Fam Pract 2002;19:476-83.

28. Hjortdahl P, Borchgrevink CF. Continuity of care: influence of general practitioners' knowledge about their patients on use of resources in consultations. BMJ 1991;303:1181-4.

29. White A. Additional concern initiations in general surgery visits: a longitudinal analysis of doctor-patient communication. Berkeley, CA: UCLA; 2017. Available from: http://www.escholarship.org/uc/item/450010j2.

30. Fenton JJ, Magnan EM, Jerant A, Kravitz RL, Franks P. Patient characteristics associated with making requests during primary care visits. J Am Board Fam Med 2019;32:201-8.

31. Atkinson NL, Saperstein SL, Pleis J. Using the Internet for health-related activities: findings from a national probability sample. J Med Internet Res 2009;11(1):e4.

32. Paterniti DA, Fancher TL, Cipri CS, Timmermans S, Heritage J, Kravitz RL. Getting to "no": strategies primary care physicians use to deny patient requests. Arch Intern Med 2010;170:381-8.

33. Fenton JJ, Kravitz RL, Jerant A, et al. Promoting patient-centered counseling to reduce use of lowvalue diagnostic tests: a randomized clinical trial. JAMA Intern Med 2016;176:191-7. 